Comunicação: Maria Luísa Faria de Sousa Cerqueira Correia Castilho

Luisa.correia@esart.ipcb.pt

\title{
A vida e a obra de Manuel de Tavares
}

\section{A Vida}

São vasta as referências ao compositor Manuel de Tavares na histografia musicológica portuguesa, embora havendo nesta muitas contradições e incorrecções, a respeito deste autor.

Todos os autores são unânimes quanto à naturalidade de Manuel de Tavares ser de Portalegre, em Portugal. No entanto, ainda não foi possível desvendar a sua data de nascimento ${ }^{1}$. A data provável que lhe tem atribuído a histografia é por volta de 1585 , o que se pensa que possa estar correcta, uma vez que a primeira data precisa que se conhece do seu percurso profissional é como Mestre de Capela em Baeza, em 1609, ano em que teria 24 anos, uma idade provável para um primeiro trabalho como Mestre de Capela.

A sua aprendizagem terá sido como discípulo de António Ferro, que era mestre de capela da Sé de Portalegre. Aos moços de coro, que tinham que ter boa voz e saberem ler, eralhes ensinado canto chão e polifonia, como atesta o Regimento da Igreja, Coro e Sé de Portalegre, de $1560 .^{2}$

Não é possível conhecer mais sobre a juventude de Manuel Tavares na Sé de Portalegre, uma vez que os poucos registos existentes no arquivo desta catedral nada contêm sobre ele. Pode-se intuir é que António Ferro, que por sua vez tinha sido discípulo do grande mestre da claustra de Évora, Manuel Mendes, tenha sido um bom mestre no ensino musical, proporcionando ao jovem Manuel de Tavares as ferramentas teóricas e práticas para o seu futuro ofício de compositor, assim como para os cargos de prestígio que conseguiu em Espanha.

\footnotetext{
${ }^{1}$ Apesar de uma exaustiva pesquisa no Arquivo Distrital de Portalegre não foi possível encontrar estes dados, até porque em algumas paróquias havia faltas quando aos registos de nascimento.

${ }^{2}$ Cónego Anacleto Pires da Silva MARTINS, O Cabido da Sé de Portalegre: Achegas para a sua história, Portalegre, 1997, p. 55.
} 
Nos finais da primeira década do século XVII encontramos Tavares como Mestre de Capela na cidade andaluza de Baeza, onde se havia estabelecido com outros familiares seus dedicados à música, nomeadamente o organista Francisco de Tavares, ao qual a 30 de Agosto de 1608, são pagos 4 ducados, por concorrer ao lugar de organista da catedral de Jaen, referindo-se-lhe o documento que mencionava este pagamento como sendo organista de Baeza. ${ }^{3}$ Quanto a Manuel de Tavares o seu nome aparece referenciado como sendo Mestre de Capela desta Catedral, com o salário habitual, no rol de pagamentos do Cabido geral da Natividade, no fim do ano de $1611 .^{4}$ Se o salário era «o habitual» era porque Manuel de Tavares já ali actuava antes, o que é confirmado pelo documento 1091-b, de Novembro de 1609, da Catedral de Las Palmas de Gran Canária, o qual tinha recebido uma carta do compositor a oferecer os seus serviços.

No entanto a sua oferta não foi aceite, e transcorreriam mais de vinte anos para que se oferecesse por segunda vez e fosse aceite em Las Palmas.

Assim, Manuel de Tavares esteve na Catedral de Baeza pelo menos desde 1609 a meados de 1612, pois a 22 de Junho deste ano vem referido no livro de autos capitulares que « vino Juan Ramirez cantor $\mathrm{v}^{\mathbf{o}}$ de murcia a pretender la plaça de $\mathrm{m}^{\mathbf{o}}$ de capilla que vaco por manuel de tabares» ${ }^{5}$, e no final do ano já não é o seu nome que figura como Mestre de Capela entre os agentes do Cabido geral da Natividade mas sim Juan Ruiz Ramírez.

As principais obrigações do Mestre de Capela eram ${ }^{6}$ dirigir o conjunto, tanto de vozes como de instrumentos, nos respectivos ensaios; compor uma série de obras obrigatórias, como vilancicos em castelhano para as distintas festividades e obras em latim; e ensinar os moços de coro ou qualquer ministro da igreja nos distintos estilos musicais de canto chão, polifonia e contraponto. Também devia informar o Cabido sobre os componentes da capela e seu

\footnotetext{
${ }^{3}$ Pedro Jiménez CAVALLÉ, La Musica en Jaen, Jaen, Diputacion Providencial de Jaen, 1991, p. 83.

${ }^{4}$ Livros de Autos Capitulares desde el Ano 1611 a 1616, Fol. 29.

${ }^{5}$ Livros de Autos Capitulares desde el Ano 1611 a 1616, Fol. 71v..

${ }^{6}$ Cf. Pedro Jiménez CAVALLÉ, La Musica en Jaen, Jaen, Diputacion Providencial de Jaen, 1991, p. 48.
} 
rendimento, além do que devia actuar como juiz nos concursos para cobrir qualquer vaga de músico, dar parecer sobre os livros de música para possível aquisição, e uma vez adquiridos exercer sobre eles certa ordem e controlo.

Manuel Tavares pôde contar na sua capela de música com cantores tiples, contraltos, tenores e «clericones», quatro menestréis não especificados e um organista (Francisco de Tavares). ${ }^{7}$

De Baeza, em 1612, muda-se para a catedral de Múrcia, para ocupar o mesmo cargo de Mestre de Capela. ${ }^{8}$ Fixa residência nesta cidade durante quase vinte anos, até ir ocupar igual cargo na Catedral de Las Palmas de Gran Canária, em 1631. 9

Segundo Lola de la Torre ${ }^{10}$, depois de várias negociações infrutíferas por parte do Cabido da Catedral de Las Palmas para contratar um Mestre de Capela, desde pelo menos 1627 é o Cónego de Sevilha Juan Manuel Suárez, representante ali do cabido canário, quem consegue resolver o problema contratando Manuel de Tavares em Maio de 1630, embora este viesse a tardar um ano inteiro em formalizar o contrato e transferir-se para Las Palmas. Começa em funções em Maio de 1631 e ali permanece até ao Verão de 1638, quando decidiu voltar à Península.

Ao chegar às Canárias, trazia consigo a sua família: sua mulher Ana Manuel, e seu filho Nicolau Tavares, a quem estava instruindo para o ofício de Mestre de Capela.

Segundo Lothar Siemens Hernández, ${ }^{11}$ Manuel de Tavares foi o mestre que consolidou o estilo policoral na catedral de Las Palmas, à qual prestava um grande contributo profissional. Por 300 ducados anuais de ordenado incorporava por sua conta o seu filho

\footnotetext{
${ }^{7}$ Francisco de Tavares esteve ao serviço da Catedral de Baeza durante a primeira metade do séc. XVII.

${ }^{8}$ Segundo informação verbal de Consuelo Trats Redondo, que realiza o seu doutoramento sobre a Catedral de Múrcia no séc. XVII e XVIII.

${ }^{9}$ Não foi possível fazer uma investigação sobre Manuel Tavares e a sua obra na Catedral de Múrcia, por o seu arquivo estar em restauro.

${ }^{10}$ Lola de la TORRE, «Documentos sobre la música en la Catedral de Las Palmas (1621-1640)», El Museo Canario, Las Palmas de Gran Canaria, 1997, p. 493.

${ }^{11}$ Lothar Siemens HERNÁNDES, «Una Obra para la copla de ministriles de la Catedral de Las Palmas de Nicolás Tavares de Oliveira (ca. 1614-1647)», in Revista de Musicología XXV, Madrid, 2002, p. 7-8.
} 
Nicolau como seu ajudante, o que abria também expectativas de futuro quanto à sucessão de mestre quando este falecesse ou se reformasse. Assim, tarefas que antigamente eram encomendadas a várias pessoas, foram sendo assumidas por Manuel de Tavares:

- O ensino dos moços de coro, pelo que ganhava mais 50 ducados, a partir de 1632 , em detrimento do titular deste ofício;

- O ensino de polifonia aos moços de coro, pelo que ganhava mais 26 doblas:

- Todos os honorários extra inerentes aos vilancicos de Natal, de Reis e de Corpo de Deus, por cuja composição e trabalho cobravam, à parte dos seus salários, as pessoas a quem estas obras eram encomendadas, as quais nem sempre eram os mestres de capela mas podiam ser também certos cantores:

- A organização das danças, autos e colóquios teatrais, nas festas do Corpo de Deus:

- A decisão sobre a selecção e admissão de novos meninos cantores para a Catedral, em detrimento das faculdades reservadas ao Deão (que protestou reiteradamente esta intromissão nas suas faculdades):

- A leccionação de canto aos capelães menores:

- Os ensaios de exercício com os instrumentistas:

Em muitas destas tarefas era Manuel Tavares coadjuvado pelo seu filho Nicolau Tavares, o que suscitou a inveja e queixas de alguns músicos, por este ter ajudado a seu pai nas suas funções docentes e de ensaios musicais sem pertencer ao quadro de pessoal da catedral. A discórdia aflorou em Setembro de 1633, quando, dois cantores, na ausência do Mestre, se enfrentaram com o seu filho e violentamente o maltrataram com insultos e injurias, pelo que foram duramente repreendidos pelo cabido:

Como não foi a única disputa, Nicolau convenceu-se de que o seu futuro não podia estar entre aquela equipa de músicos tão hostil e assim, como já estava formado 
profissionalmente e com idade de assumir o ofício de Mestre de Capela, começou a procurar trabalho na Península, até que conseguiu, no Verão de 1637, ir para Cádiz.

A estabilidade de Nicolau era o que o seu pai esperava para também regressar das Canárias para a Península. Pretendeu primeiro retomar o seu ofício na Catedral de Múrcia, mas sem o conseguir, e finalmente é contratado pela Catedral de Cuenca, depois de terem lugar várias negociações durante alguns meses, tomando posse do cargo em Setembro de 1638, usufruindo do salário de 400 ducados e 30 fanecas de trigo.

Quando Tavares partiu, no Verão de 1638, comprometeu-se a contratar um bom sucessor seu para a Capela da catedral canária, assim como a vários cantores de qualidade, o que realizou pontualmente, e também vendeu ao Cabido uma colecção de salmos, hinos, motetes, paixões e ofícios da Semana Santa e ainda duas missas, não se expressando quais destas obras eram de sua autoria .

Manuel de Tavares terá começado o seu ofício na Catedral da Cuenca em meados de Setembro, no entanto talvez pela mudança de ares ou pela viajem terá adoecido gravemente, pois, no folio 117 , de 5 de Outubro «El Cabildo da cuenta de una petición de su mujer e hijos de ayuda por su pobreza y necesidad» ${ }^{12}$. E também se dá conta de uma Junta extraordinária para prover um Mestre de Capela. Só se compreende esta Junta se se pensar que Tavares estaria mesmo num estado muito precário de saúde. A Junta acordou por maioria de votos chamar o seu filho, Nicolau Tavares, para ser o novo Mestre de Capela. Este encontrava-se como Mestre de Capela em Cádiz e a Junta referiu-se a ele com as seguintes palavras: «...de mucha opinión en su Magisterio y de mucha virtud, com un salario de 400 ducados y 30 fanegas de trigo» ${ }^{13}$.

Efectivamente a Junta tinha razão ao pensar que a morte devia estar para breve, uma vez que Manuel de Tavares faleceu poucos dias depois, a 14 de Outubro de 1638.

\footnotetext{
${ }^{12}$ Actas Capitulares, f. 117, de 5 de Outubro.

${ }^{13}$ Ibidem
} 
A situação da sua morte deve ter sido muito delicada para o seu filho Nicolau, que provavelmente estava em Cuenca, pois passados apenas dois dias morreu igualmente a sua mãe, Ana Manuel, mulher de Manuel de Tavares, vitima provavelmente de algum colapso ou enfarte.

O casal Manuel de Tavares e Ana Manuel tinha mais filhos pequenos, e assim Nicolau teve que acolher em casa os seus irmãos. Esta situação foi a partir daí bastante complicada porque Nicolau tinha também a sua própria família, com mulher e filhos. Como tal, não é de estranhar as dificuldades financeiras no seu lar que se referem na nota do cabido em 1644.

Tendo em conta as referências que o Cabido tecia sobre Nicolau, a quem consideravam um excepcional Mestre, podemos intuir que o pai e professor, Manuel de Tavares, terá sido também um grande pedagogo, numa linha pedagógica distinta começada na Sé de Évora por Manuel Mendes.

\section{A Obra}

Actualmente a obra de Tavares conta com um acervo de 28 obras sobreviventes, oriundas das Catedrais de Baeza, Las Palmas de Grã Canária, Valência, Saragoça, Salamanca e Puebla (México). ${ }^{14}$

Em geral podemos constatar que a obra de Manuel de Tavares, cuja linguagem contrapontística é já significativamente progressiva, tanto temos vestígios de pendor mais tradicional como nos deparamos com características desenvolvidas em matéria de linguagem modal e polifónico-contrapontística. Conclui-se, como tal, que Tavares, num entendimento profundo da laboração do contraponto, ora se mantém fiel aos legados da tradição, como

\footnotetext{
${ }^{14}$ Existem também na Catedral de Múrcia obras de Manuel de Tavares, no entanto no decurso desta investigação não foi possível o seu estudo porque o seu arquivo se encontrar em obras de restauro
} 
explora profusamente os arquétipos de uma nova linguagem emergente, criando uma síntese complexa e original do ponto de vista estilístico-formal. Particularmente, dos vários parâmetros da análise musical abordados, uns há que se aproximam mais do primeiro caso, outros do segundo.

Podemos sistematizar a obra de Manuel de Tavares duas grandes categorias: as obras Monocorais e as Policorais; e em cinco géneros, sendo quatro músico-litúrgicos (Missa, Ofício, Motete e Vilancico) e o outro género contando apenas com uma obra profana, um Romance. No que respeita aos géneros músico-litúrgicos, observa-se que a escolha dos textos predominam os que contêm uma acentuada carga emocional, e que ao mesmo tempo dão cumprimento ao modelo pós-tridentino. Como tal, neste domínio o compositor insere-se perfeitamente dentro da tradição maneirista que caracterizava a música Ibérica na primeira metade do século XVII.

A escolha do efectivo vocal para a composição das obras por parte de Manuel de Tavares revelou-se bastante diversificada, contendo obras monocorais a quatro, cinco e seis vozes e obras policorais a sete, oito e nove vozes em dois coros e a dez, onze, doze e treze vozes em três coros. Quanto à textura evidencia-se claramente a relação directa que existe entre um discurso policoral a dois ou três coros e a preferência por uma concepção mais homofónica e vertical do discurso polifónico. A disposição simultânea de um grande número de número de vozes tem como resultado que nesse aglomerado sonoro se tornem virtualmente inaudíveis quaisquer linhas melódicas que não sejam as vozes mais agudas e o Baixo. Além disso, como é natural numa obra policoral, a arquitectura do enredo polifónico será menos dirigido para o entrelaçar das linhas vocais individuais, e mais concebida em função do diálogo ou oposição entre duas ou três estruturas polifónicas (dois ou três coros). Assim 
evidencia-se uma escrita mais homofónica para as obras policorais, em que o contraste se faz através do recurso a texturas de contraponto imitativo ou livre. Nas obras monocorais passa-se a situação inversa, em que há um predomínio da imitação e o contraste obtém-se através da homofonia ou do contraponto livre.

No que se refere à estrutura formal são utilizados variadas técnicas, com uma enorme complexidade orgânica, as quais indicam um importante elemento diferenciador em termos estilísticos. Por um lado, temos composições estruturadas mais dentro do espírito estilístico dominante da tradição polifónica quinhentista, e que recorrem a formas modeladas a partir da estrutura litúrgica dos textos, em que predomina um tipo de contraponto imitativo. Por outro lado temos outras composições que têm já aspectos ligados à mudança, nomeadamente nas obras policorais.. Nestas obras dá-se agora lugar a padrões formais de repetição motívica reiterada, onde predomina uma textura homofónica, quer de formas musicais estróficas, em que aproveitam a particularidade do texto mas, simultaneamente, se afastam delas por uma lógica puramente musical, assim nestas composições as questões formais são determinadas por razões de pura sonoridade e expressão intrinsecamente musical.

A apreciação global dos diversos enquadramentos modais, domínio em que utiliza em grande número os chamados modos novos, leva à ilação de que as composições de Manuel de Tavares manifestam com maior ou menor grau de insistência um empenho de descontextualização modal, o qual motiva, não raras vezes, um discurso polifónico de características harmónico-funcionais, saliente pela presença de notas de atracção e de relações funcionais do tipo Dominante-Tónica enunciadas pelo Baixo. Do ponto de vista históricoestilístico, a dialéctica entre a modalidade tradicional e os hibridismos que a distorcem em 
harmonias funcionais situam o compositor numa dualidade entre uma linguagem mais tradicional ou maneirista e uma mais inovadora ou pré-barroca.

Do ponto de vista cadencial, existe uma fortíssima propensão efectiva por parte de Tavares para utilizar as cláusulas harmónicas. Quando usa cláusulas contrapontísticas estas são acrescidas com uma voz grave descrevendo o movimento V-I, tendo como consequência um conteúdo proto-harmónico. Este dado é bastante significativo da atenção que o compositor, uma vez mais, demostra ter para com as potencialidades proto-harmónicas ou mesmo harmónicas inerentes a um discurso polifónico já bastante desenvolvido.

No que respeita ao tratamento da dissonância há uma certa liberdade de regras comparativamente aos tradicionais modelos polifónicos. Em Manuel de Tavares, no que refere à elaboração da dissonância, talvez mais do que qualquer outro, verificamos uma subversão efectiva da regulamentação contrapontística herdada pela prática maneirista, em favor da aproximação aos novos conceitos estabelecidos pelo barroco. Tudo isto se torna visível na frequente exposição da dissonância sem a preparação regulamentar, na concepção vertical da escrita que constantemente utiliza, bem como na formação de dissonâncias unicamente fundamentadas por uma lógica harmónica concreta. Por estas características não quer dizer que o compositor se tenha afastado em absoluto dos procedimentos contrapontísticos maneiristas. Estes, como é evidente, encontram-se igualmente presentes, revelando-se nomeadamente na forma como através de um movimento melódico regular, logo, através de uma concepção horizontal, são introduzidas tão frequentemente dissonâncias apenas entendidas enquanto inseridas nesse mesmo contexto. Assim, ao nível da dissonância, sustenta-se, como tal, um comportamento ambivalente. Uma dinâmica de transição entre o «horizontal» e o «vertical»; entre o contrapontístico e o harmónico; entre o modal e o tonal. 
O carácter da invenção temática e motívica, as variadas técnicas de articulação dos motivos e a própria relação do discurso polifónico com o material pré-existente, ou novo, são dados bem demonstrativos do facto de nos encontrarmos perante uma arquitectura polifónicocontrapontística extraordinariamente desenvolvida.

Quanto à relação expressiva entre texto e música, as composições de Manuel de Tavares inserem-se num tipo de repertório que do ponto de vista semântico e retórico integra a sensibilidade estética maneirista de finais do século XVI e princípios do XVII, onde havia uma preocupação expressiva e de respeito pelo texto, isto é, adequar a música ao sentido das palavras, exprimindo a força de cada emoção diferente. Assim, no sentido de servir eficaz e pormenorizadamente as palavras do texto usava uma técnica de ilustração ou simbolismo musical mediante o qual se utilizavam na composição relações extramusicais com o objectivo de afirmar a expressividade textual, tais como: configurações melódicas e rítmicas, cromatismos, dissonâncias, melismas sobre certas sílabas, falsas relações, ornamentos, contrastes introduzidos na textura contrapontística, etc.

Em conclusão podemos afirmar que estamos perante um repertório musical no qual convivem e se cruzam, em simultâneo, um stile antico modernizado, alargado a novos elementos de uma escrita harmónica, e um stile moderno que agrega já o fundamental de um discurso policoral, concertante e apoiado na técnica do baixo contínuo. O apelo interpolado a distintos códigos estilísticos pelo compositor, consoante as preferências das circunstâncias, parece apontar para uma postura musical característica da estética barroca. 